\title{
Social organizations and cultural influences in the age of social media concerning societal fragmentation
}

\author{
Ho Manh Tung \\ Ritsumeikan Asia Pacific University \\ Beppu, Oita, Japan
}

September 29, 2020

I have a pleasure listening to Sam Harris and Tristan Harris discussing Tristan's new Netflix documentary "Social Dilemma" on Sam's podcast "Making Sense" in his No. 218 episode titled "Welcome to the cult factory" recently (Harris, 2020). Both of them are careful thinkers, seekers of practical solutions for the fragmentation of society due to social media. Sam Harris uses the analogy of a "cult factory" to describe how social networks quickly generate so many sub-cultures and sub-communities whose beliefs and ideologies can be as crazy as they are unchecked. The speakers convey a sense of urgency to respond to such a speedy fragmentation going on in society. Individuals can be physically together but universes apart regarding what information they are getting from their social media news feeds.

There seems to be no legal framework on sight to monitor this problem. Both social media companies and governments cannot agree on whether these social media companies should be viewed as merely platforms or publishers. Moreover, even if hypothetically, everyone agrees on what role these companies should play, the process of passing new legislations can 
never catch up with the speed of changes in the hyperconnected cyberworld. Each new social media platform presents a unique set of challenges. And their country of origin means there would not be a globally unifying response to each of them. TikTok is different from Instagram. Weibo is different from Facebook in both what they offer as user experiences and politically. And who knows which kind of new platforms will emerge tomorrow?

Tristan Harris raises an interesting point that the only thing that can catch up or provide a fast-enough response to the memetic challenges of social media is culture. He calls for a new culture of fact-checking, unfollowing targeted news, unfollowing outrage media, etc. It seems, at minimum, a very interesting take: only a dominant culture of rational criticism, empirical and impassioned discussion can counter the spread of unchecked information, outrageous memes, and conspiracies. It might be due to the podcast episode coming to an end, but there is no further discussion on instituting such cultural changes. I hope to offer some solution here by pointing out the potential role social organizations can play in instituting such cultural changes.

Non-profit and non-commercial social organizations can be more ready than the governments and the market in responding to cultural changes in social media. It seems to me social organizations can play a role of cultural monitoring due to their strengths in 1) adaptability; 2) memetic power; and 3) credibility.

For their adaptability, social organizations are not subject to the huge bureaucratic machine that holds back government institutions in quickly responding to drastic socio-cultural changes. Their adaptability is key to provide counter-narratives for any social movements that run on the emotional discharges that happen due to social media: for example, the \#defundthepolice or the \#shutdownSTEM movement. 
Moreover, by not representing any commercial entities or government institutions, social organizations, once they have any credibility and sustainability, are, by definition, un-cancellable. This is especially useful in the age of cancel culture. Being non-profit and non-organizational means that social organizations are merely groups of people who come together to solve certain problems they deem meaningful. This can help increase their credibility when social organizations decide to raise their concerns about certain social movements.

In terms of memetic power, there are many examples throughout history of non-profit and non-organizational social organizations creating memetic changes in the world for better and for worse. Take a positive example, GiveWell, who provides a ranking of the most economically effective charities, has helped redirect 100 million US dollars to effective charities worldwide (McAskill, 2017). Clearly, social organizations like this can be very powerful in redistributing resources towards neglected problems in society and helping to maintain social solidarity. The power of GiveWell is that it is propagating the innovative memes about doing charity, philanthropy, social work, which are based on the well-thought-out philosophy of effective altruism (MacAskill, 2015; Berkey, 2017).

Seeing the advantages of social organizations, there are three areas where I think researchers can look further to understand how social organizations can be helpful. The first problem is related to public shaming. Although social media causes a dark turn to public shaming (Ronson, 2016; Kasra, 2017), the proper sense of shame and public rituals to rehabilitate people's reputation can be an area on which social organizations can focus. It seems that the literature on the culture of honor (Sommers, 2009, 2018) and social harmony can be useful here (Vuong et al., 2018, 2020). 
Regarding the problem of misinformation and disinformation, what Tristan Harris is calling for when he advocates the several above-mentioned cultural changes in the way people consume content in social media is a kind of GiveWell organization in public epistemology. Public epistemology, especially public epistemology in the age of social media, is arguably a very under-researched area.

If we take the Geert Hofstede's theory of cultural dimensions, the arrival of social media has amplified the dimensions of individualism, avoidance of uncertainty, short-termism, and emotional indulgence (Hofstede, 2001, 2011). The task of social organizations is to push back against these trends: generating a culture that tends toward a more collectivist/holistic thinking, a more tolerance of uncertainty and nuances, a higher emphasis on long-termism, and a higher priority on self-restraint. Most probably, it will take the mindsponge workhorse to guide our cultural perceptions in a world where too many unfamiliar and emerging values have been brought into sight recently and unstoppably (Vuong \& Napier, 2015).

\section{References}

Berkey, B. (2017). the institutional critique of effective altruism. Utilitas, 30(2), 143-171. doi:10.1017/S0953820817000176

Harris, S. (2020). (Producer). (2020, September 24). \#218 - Welcome to the cult factory: A Conversation with Tristan Harris [Audio Podcast]. Retrieved from https://samharris.org/podcasts/218-welcome-cult-factory/

Hofstede, G. (2001). Culture's Consequences: comparing values, behaviors, institutions, and organizations across nations (2nd ed.). Thousand Oaks, CA: SAGE Publications. 
Hofstede, G. (2011). Dimensionalizing cultures: The Hofstede model in context. Online readings in psychology and culture, 2(1), 2307-0919.

Kasra, M. (2017). Vigilantism, public shaming, and social media hegemony: The role of digitalnetworked images in humiliation and sociopolitical control. The Communication Review, 20(3), 172-188.

MacAskill, W. (2015). Doing good better: Effective altruism and a radical new way to make a difference. Guardian Faber Publishing.

MacAskill, W. (2017). Effective altruism: introduction. Essays in Philosophy, 18(1), 1-5.

Ronson, J. (2016). So you've been publicly shamed. Riverhead Books.

Sommers, T. (2009). The two faces of revenge: moral responsibility and the culture of honor. Biology \& Philosophy, 24(1), 35-50.

Sommers, T. (2018). Why honor matters. Basic Books.

Vuong, Q.-H., Bui, Q.-K., La, V.-P., et al. (2018). Cultural additivity: behavioural insights from the interaction of Confucianism, Buddhism and Taoism in folktales. Palgrave Communications, 4(1), 143.

Vuong, Q.-H., Ho, M.-T., Nguyen, H.-K. T., et al. (2020). On how religions could accidentally incite lies and violence: folktales as a cultural transmitter. Palgrave Communications, $6(1), 82$.

Vuong, Q. H., \& Napier, N. K. (2015). Acculturation and global mindsponge: an emerging market perspective. International Journal of Intercultural Relations, 49, 354-367. 